\title{
Evaluation of combined homograft replacement of aortic valve and coronary bypass grafting in patients with aortic stenosis ${ }^{1}$
}

\author{
RICHARD THOMPSON, MOHAMMED AHMED, CHARLES ILSLEY, \\ RICARDO SEABRA-GOMES, ANTHONY RICKARDS, AND MAGDI YACOUB \\ From Harefield Hospital, Harefield, Middlesex, and National Heart Hospital, London
}

SUMMARY Between January 1972 and October 1977, 40 patients with aortic stenosis underwent combined homograft replacement of the aortic valve and coronary artery bypass grafting. There were 29 men and 11 women between the ages of 38 years and 69 years (mean 58 years). Twenty-nine patients (73\%) were in class III or IV of the NYHA Classification at the time of operation. Peak systolic aortic valve gradients ranged from 30 to $150 \mathrm{mmHg}$ (mean $77 \mathrm{mmHg}$ ). Twelve patients $(30 \%)$ had triple vessel disease, 13 $(33 \%)$ had double vessel disease, and $15(37 \%)$ had single vessel disease. Left main stem stenosis was present in four $(10 \%)$. Altogether 59 grafts were inserted (average 1.5 grafts per patient). There were one early death $(2.5 \%$ ) and two late deaths $(5 \%)$ during a follow-up between six and 62 months (mean 26 months). Thirty-three patients $(89 \%)$ moved to class I of the NYHA Classification after operation. Four patients $(10 \%)$ sustained perioperative infarction without deterioration in clinical status. Nineteen patients were reinvestigated by repeat left ventriculography and by graft and coronary angiography between three and 31 months (mean 12 months) after operation. The overall graft patency rate was 92 per cent. Left ventricular function was assessed by computerised radial analysis of segmental wall motion. Abnormalities of segmental wall motion in 12 patients were improved in eight (75\%). All these patients had patent grafts. Deterioration in segmental wall motion occurred in two patients $(17 \%)$ and was associated with graft occlusion in one and myocardial infarction in the other. In two patients abnormalities of segmental wall motion persisted. Both of these patients had had a myocardial infarction before operation.

Combined homograft replacement of the aortic valve and coronary artery bypass grafting gives good clinical results, with a low early and late mortality. Improvement in left ventricular function occurs in the majority of patients.

Coronary artery disease not uncommonly occurs in patients with aortic stenosis, with a reported incidence varying between 22 and 64 per cent (Basta et al., 1975; Harris et al., 1975; Mandal and Gray, 1976; Moraski et al., 1976; Paquay et al., 1976; Hancock, 1977; Thompson et al., 1979a). Previous studies have shown that isolated valve replacement in such patients may be associated with a high mortality both early and late (Linhart and Wheat, 1967; Linhart et al., 1968). The influence of additional coronary artery bypass grafting on late prognosis and the prevention of myocardial infarction still remains uncertain. The purpose of this paper is to analyse the early and long-term results

'Supported in part by the British Heart Foundation.

Received for publication 2 February 1979 of this combined procedure in a series of patients with aortic stenosis and to evaluate changes in left ventricular function after operation.

\section{Subjects and methods}

Between January 1972 and October 1977, 40 patients with aortic stenosis had operations (by M.Y.) for homograft replacement of the aortic valve and coronary artery bypass grafting at Harefield Hospital or the National Heart Hospital. There were 29 men aged between 38 and 69 years (mean 57 years) and 11 women aged between 38 and 69 years (mean 57 years). All patients were symptomatic and $29(73 \%)$ were in functional class III or IV of the New York Heart Association Classification at the time of 
operation. The duration of symptoms ranged from five to 144 months (mean 40 months). Thirteen patients $(33 \%)$ presented with angina alone, 25 patients $(63 \%)$ with angina and dyspnoea, and two patients $(4 \%)$ with dyspnoea alone. Seven patients $(18 \%)$ had experienced effort syncope (Table 1 ).

Table 1 Presenting symptoms in 40 patients undergoing combined coronary artery bypass grafting and aortic valve replacement

\begin{tabular}{lcc}
\hline Symptoms & No. & $\%$ \\
\hline Angina alone & 13 & 33 \\
Angina and dyspnoea & 25 & 63 \\
Dyspnoea alone & 2 & 5 \\
Syncope & 7 & 18 \\
\hline
\end{tabular}

The electrocardiogram showed the changes of left ventricular hypertrophy with associated ST-T changes in 29 patients $(73 \%)$, left ventricular hypertrophy on voltage criteria alone in four patients $(10 \%)$, and ST-T changes in the absence of left ventricular hypertrophy or digitalis in seven patients $(17 \%)$. Changes of previous transmural myocardial infarction were present in eight patients $(20 \%)$ and were anterior in three and inferior in five. Conduction defects were present in seven patients $(17 \%)$, and included left bundle-branch block in four, right bundle-branch block in two, and bifascicular block in one.

Before operation all patients underwent right and left heart catheterisation after overnight fasting and premedication with atropine $0.01 \mathrm{mg}$ per $\mathrm{kg}$ and diazepam $0.15 \mathrm{mg}$ per $\mathrm{kg}$. After measurement of peak systolic aortic valve gradient and left ventricular end-diastolic pressure, cine left ventriculography was performed in the right anterior oblique projection with the injection of approximately $45 \mathrm{ml} 70$ per cent sodium iothalamate (Conray 420 ) at $14 \mathrm{ml}$ per second, using a Contrac injector, and filmed at 50 frames per second with an Arriflex camera. Coronary angiography was performed using the methods described by Sones and Judkins. A 70 per cent or greater narrowing of a major coronary artery was taken as evidence of significant coronary artery disease. The haemodynamic findings are summarised in Table 2. Peak systolic aortic gradients varied

Table 2 Preoperative haemodynamic findings

\begin{tabular}{ll}
\hline Peak systolic aortic valve gradient (mmHg) & $30-150$ (mean 77$)$ \\
Aortic valve area $\left(\mathrm{cm}^{2}\right)$ & $0 \cdot 30-0 \cdot 70$ (mean 0.52$)$ \\
Left ventricular end-diastolic pressure & \\
$\quad(\mathrm{mmHg})$ & $4 \cdot 0-30 \cdot 0$ (mean 17.0) \\
Ejection fraction & $0 \cdot 33-0 \cdot 88($ mean $0 \cdot 60)$ \\
Cardiac index $\left(1 / \mathrm{min}\right.$ per $\left.\mathrm{m}^{2}\right)$ & $1 \cdot 2-4 \cdot 3$ (mean $2 \cdot 4)$ \\
\hline
\end{tabular}

between 30 and $150 \mathrm{mmHg}$ (mean $77 \mathrm{mmHg}$ ). Only four patients had a gradient less than $50 \mathrm{mmHg}$ and all had severe stenosis as judged by a calculated valve area of less than $0.50 \mathrm{~cm}^{2}$ and low cardiac output (cardiac index less than $2.0 \mathrm{l} / \mathrm{min}$ per $\mathrm{m}^{2}$ ). No patient had more than mild aortic regurgitation at aortography. Ejection fraction ranged from 0.33 to 0.88 (mean 0.60 ) and left ventricular end-diastolic pressure from 4 to $30 \mathrm{mmHg}$ (mean $17 \mathrm{mmHg}$ ).

The distribution of coronary artery disease is shown in Table 3. Significant disease was present

Table 3 Distribution of coronary artery disease

\begin{tabular}{lcc}
\hline Coronary artery & No. & $\%$ \\
\hline Anterior descending & 30 & 75 \\
Right coronary artery & 26 & 65 \\
Circumflex artery & 18 & 45 \\
Left main stem & 4 & 10 \\
\hline
\end{tabular}

in the anterior descending artery in 30 patients $(75 \%)$, in the right coronary artery in 26 patients $(65 \%)$, and in the circumflex artery in 18 patients $(45 \%)$. In addition, four patients $(10 \%)$ had greater than 70 per cent stenosis of the left main coronary artery. Single vessel disease was present in 15 patients $(38 \%)$, double vessel disease in 13 patients $(32 \%)$, and triple vessel disease in 12 patients $(30 \%)$.

In all patients the aortic valve was replaced by a fresh, unstented, antibiotic sterilised homograft, with continuous coronary perfusion at $30^{\circ} \mathrm{C}$ (Yacoub et al., 1973). Valve replacement was performed before bypass grafting except in four patients, in whom one of the coronary ostia was too small to permit cannulation. In these patients bypass grafting was performed first and coronary perfusion continued via the bypass graft. Two patients had additional mitral valvotomy and in eight patients a new method of replacing the aortic valve and root was used, with reimplantation of the coronary arteries into the coronary ostia of the homograft valve (Gula et al., 1976). A total of 59 grafts was inserted (average 1.5 grafts per patient) and included 30 to the anterior descending, 20 to the right coronary artery, and nine to the circumflex system. The presence of diffuse peripheral coronary artery disease or failure to opacify the distal coronary vessel at angiography were not regarded as contraindications to bypass grafting. Additional gas endarterectomy was performed in seven patients $(18 \%)$. The total duration of cardiopulmonary bypass was between 90 and 240 minutes (mean 130 minutes).

Nineteen patients were electively reinvestigated by repeat cardiac catheterisation including coronary and graft angiography, and left ventriculography at times between three and 31 months (mean 12 months) after operation, subject to informed consent. Left ventricular function was analysed before and after operation in these 19 patients by 
computerised radial analysis of segmental wall motion (Rickards et al., 1977). The cineventriculogram was projected on a Vanguard projector and selected frames digitised with an ultrasonic coordinate convertor (Graf/Pen) on line with an HP $2100 \mathrm{~A}$ computer. Ejection fraction was determined by the single plane area-length method (Sandler and Dodge, 1968). End-diastolic and end-systolic frames were superimposed using the mid-point of the aortic valve and the geometric centre of gravity of the end-systolic frame as fixed reference points. Radials were automatically plotted from the centre of gravity to the ventricular perimeter at $4^{\circ}$ intervals in a clockwise direction starting at the mid-point of the aortic valve. Segmental wall motion was expressed as the percentage shortening along these radials from end-diastole to end-systole, and was plotted against the radial angle (in degrees) around the ventricular perimeter (see Fig. 7). An abnormality was defined as five consecutive radials $\left(20^{\circ}\right.$ or $5 \%$ of the ventricular perimeter) greater than two standard deviations outside control values obtained from a group of patients with normal ventriculograms. Quantitative changes in segmental wall motion were expressed as changes in the percentage of the ventricular perimeter exhibiting abnormal motion (see Fig. 6). Statistical analysis of data was performed using a one-tailed paired $t$ test. Normalisation of the data by logit transformation before analysis did not influence the result.

\section{Results}

There was one early death $(2.5 \%)$ after operation, and there were two late deaths $(5 \%)$ during a followup period between six and 62 months (mean 26 months). The early death occurred at the time of operation in a patient with poor ventricular function who could not be weaned from cardiopulmonary bypass, despite the use of intra-aortic counterpulsation. This patient had severe left coronary ostial and main stem stenosis with complete occlusion of the right coronary ostium. The two late deaths both occurred at two months after operation, one as a result of Candida endocarditis with subsequent dehiscence of the aortic suture line, and the other as a result of bronchopneumonia. Necropsy in the latter patient showed the graft to be patent and the homograft to be functioning normally. Actuarial analysis of survival in this group is shown in Fig. 1 in comparison to that of 399 patients undergoing isolated, elective homograft replacement of the aortic valve at Harefield Hospital over a similar time period. Neither early nor late mortality at five years were significantly different in the two groups. However, the duration of follow-up in the combined group is shorter and further evaluation is necessary.

All patients were improved after operation and 33 $(89 \%)$ moved to class I of the New York Heart Association Classification (Fig. 2). Perioperative myocardial infarction, as judged by the appearance of new pathological $Q$ waves or the development of poor $\mathbf{R}$ wave progression across the chest leads, occurred in four patients $(10 \%)$ without mortality or deterioration in clinical status. In three patients the infarct was anterior and in one patient it was both anterior and inferior. The infarct in each case was in the territory of a grafted vessel. Two of these patients were subsequently reinvestigated and in both cases the graft to the infarcted area was found to be patent with good distal run-off; in one there was significant deterioration in left ventricular function. So far no patient has had a late myocardial infarction. Electrocardiographic signs of left ventricular hypertrophy regressed in most patients and the electrocardiogram has returned to normal in 32 patients (86\%) (Fig. 3).

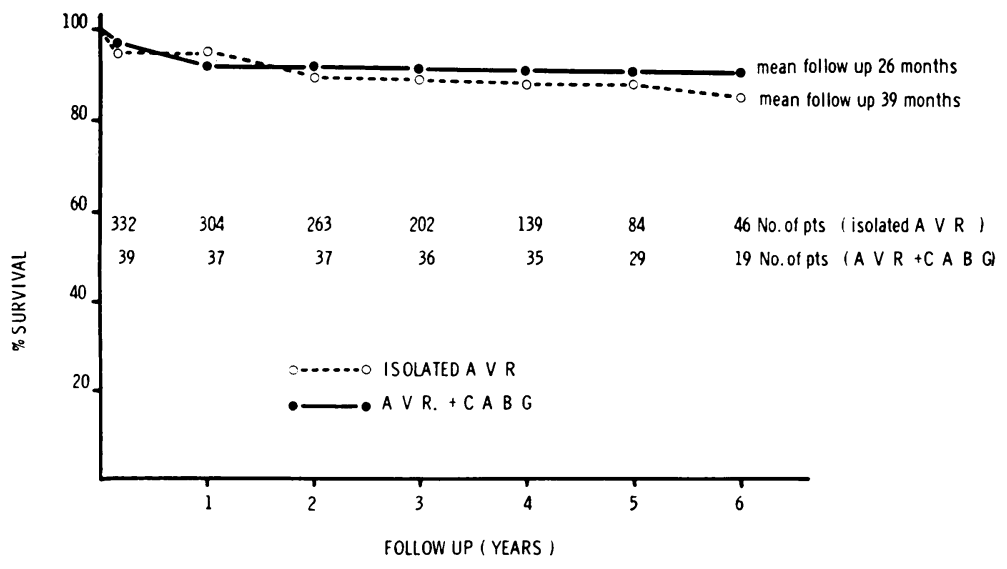

Fig. 1 Actuarial analysis of survival after combined aortic valve replacement and coronary artery bypass grafting compared with that of 339 patients undergoing isolated, elective aortic valve replacement at Harefield Hospital. 
FUNCTIONAL CLASS

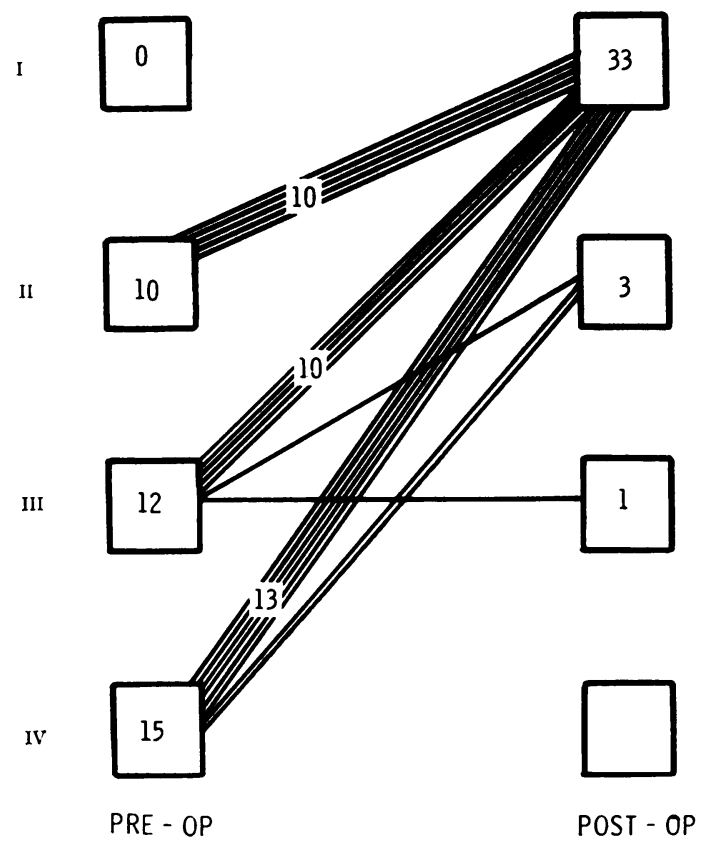

Fig. 2 Regression of symptoms after combined aortic valve replacement and coronary artery bypass grafting.

Nineteen patients were reinvestigated at times between three and 31 months (mean 12 months) after operation. Altogether 26 grafts were inserted in this group. At reinvestigation all grafts were entered and $24(92 \%)$ were found to be patent.

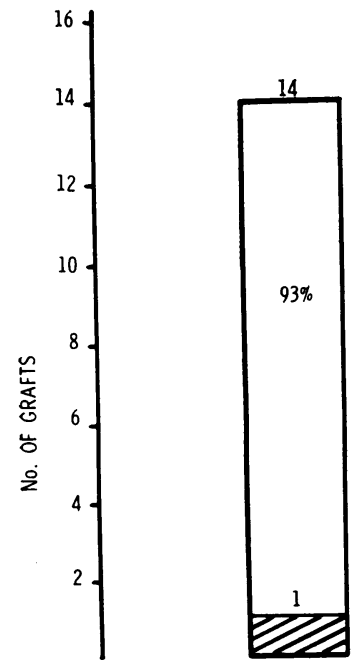

ANTERIOR DESCENDING ARTERY

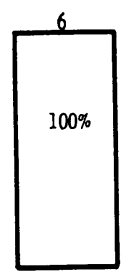

CIRCUMFLEX ARTERY
NO L V H

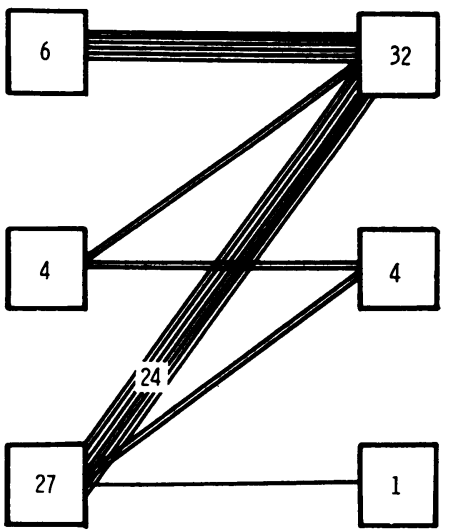

PRE - OP

POST - OP

Fig. 3 Regression of electrocardiographic signs of left ventricular hypertrophy after operation.

Graft patency did not appear to be influenced by the particular artery grafted (Fig. 4).

Analysis of the group as a whole showed a significant increase in ejection fraction after operation from a mean of 0.63 to $0.72(t=2.28, P<0.025)$ (Fig. 5). If this group is divided into patients with a normal preoperative ejection fraction (greater than 0.70 ) and those with a reduced ejection fraction, there was no significant change in ejection fraction after operation in the former group $(t=0.71$, $P>0.5)$. There was, however, a significant increase in ejection fraction in patients with a preoperative ejection fraction less than $0.70(t=3.26, P<0.005)$.

In the group as a whole there was also a signi-

Fig. 4 Graft patency in relation to the particular artery grafted. 
EJECTION FRACTION
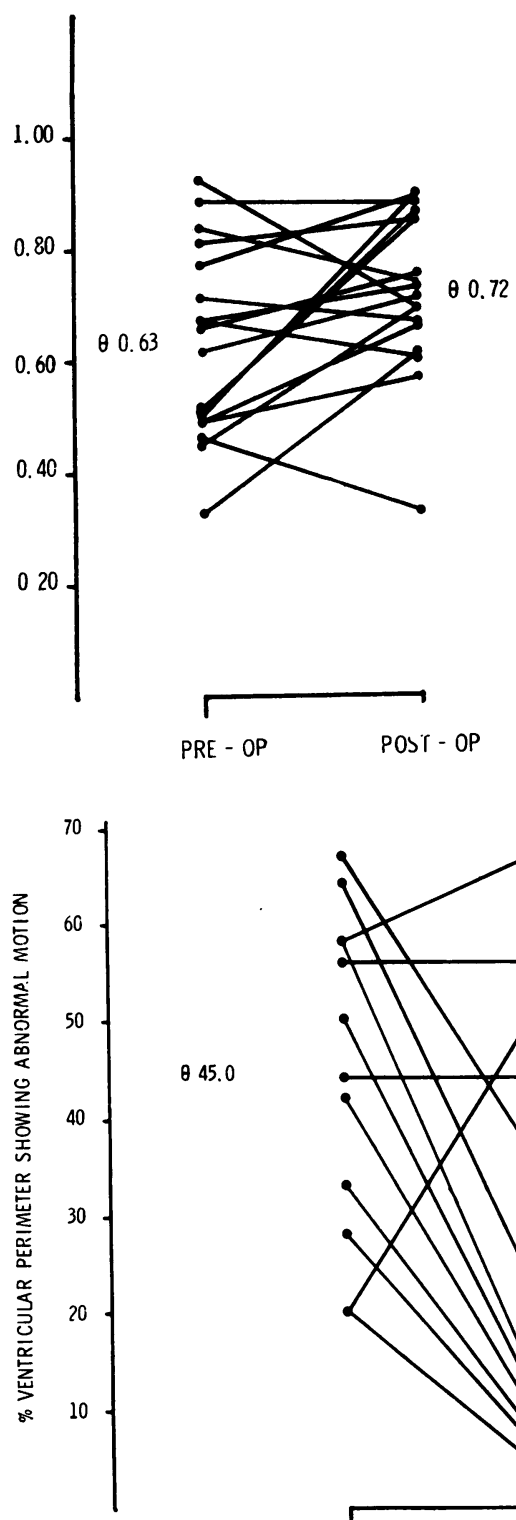

LVEDP ( $\mathrm{mm} \mathrm{Hg})$

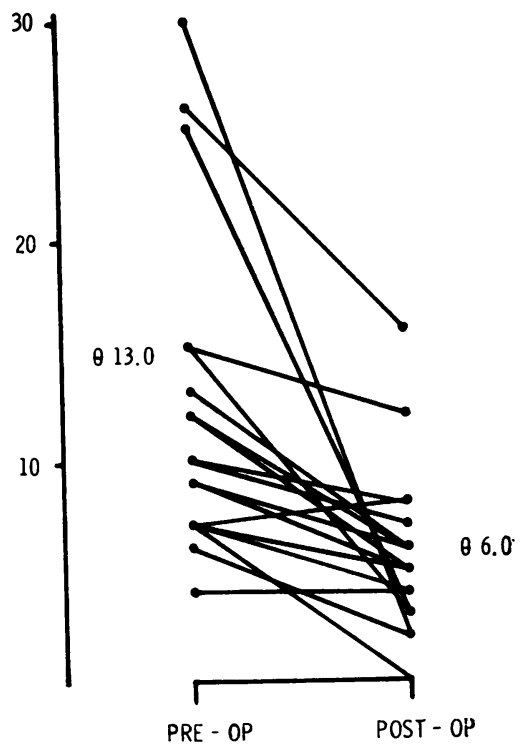

Fig. 5 Changes in ejection fraction and left ventricular end-diastolic pressure after operation.

Fig. 6 Quantitative changes in segmental wall motion after combined aortic valve replacement and coronary artery bypass grafting.

ficant decrease in left ventricular end-diastolic pressure from a mean of $13 \mathrm{mmHg}$ to a mean of $6 \mathrm{mmHg}$ (Fig. 5) $(\mathrm{t}=3.91, \mathrm{P}<0.0015)$.

Analysis of segmental wall motion in these 19 patients before operation showed localised abnormalities of wall motion in nine patients (47\%),

generalised hypokinesia in three patients (16\%), and a normal pattern of contraction in seven patients $(37 \%)$. After operation localised abnormalities of wall motion improved in six of the nine patients $(67 \%)$ (Table 4$)$, deteriorated in one patient, and

Table 4 Changes in left ventricular contraction pattern in 19 patients after aortic valve replacement and coronary artery bypass grafting

\begin{tabular}{|c|c|c|c|}
\hline $\begin{array}{l}\text { Contraction pattern before } \\
\text { operation }\end{array}$ & Improved & Unchanged & Deteriorated \\
\hline $\begin{array}{l}\text { Normal (7) } \\
\text { Localised wall motion }\end{array}$ & 0 & 7 & 0 \\
\hline $\begin{array}{l}\text { abnormalities (9) } \\
\text { Generalised hypokinesia (3) }\end{array}$ & $\begin{array}{l}6 \\
2\end{array}$ & $\begin{array}{l}2 \\
0\end{array}$ & $\begin{array}{l}1 \\
1\end{array}$ \\
\hline
\end{tabular}

were unchanged in two patients. The two patients showing no change in wall motion abnormalities had both had a myocardial infarction before operation. The one patient showing deterioration had sustained perioperative infarction. Of the three patients with generalised hypokinesia preoperatively, two subsequently improved, and one showed further deterioration; in the latter case the deterioration was associated with occlusion of a graft to the affected segment. The seven patients with a normal pattern of contraction preoperatively were found to be unchanged at reinvestigation.

Quantitative changes in segmental wall motion in the 12 patients with abnormal motion before operation (localised or generalised) are shown in Fig. 6. The percentage of the ventricular perimeter showing abnormal motion decreased after operation from a 
mean of 45 per cent to a mean of 22 per cent $(t=$ $2.67, \mathrm{P}<0.015)$. Normal wall motion was restored in six patients $(50 \%)$. Improvement in wall motion with residual abnormalities occurred in two patients $(17 \%)$, remained unchanged in two patients $(17 \%)$, and deteriorated in two patients $(17 \%)$.

Fig. 7 a-c show examples of pre- and postoperative analysis of segmental wall motion. Fig. 7a illustrates a patient with predominantly inferior hypokinesia before operation which returned to normal apart from a minor abnormality at the site

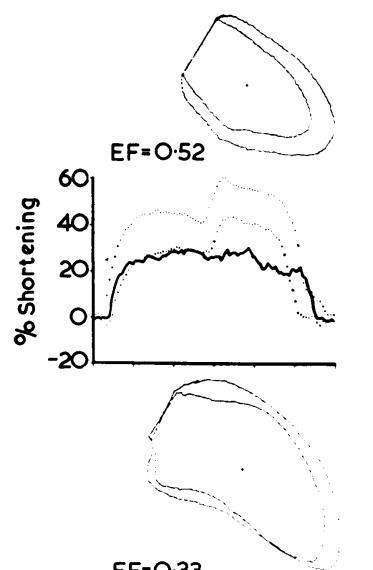

$\underline{9}$
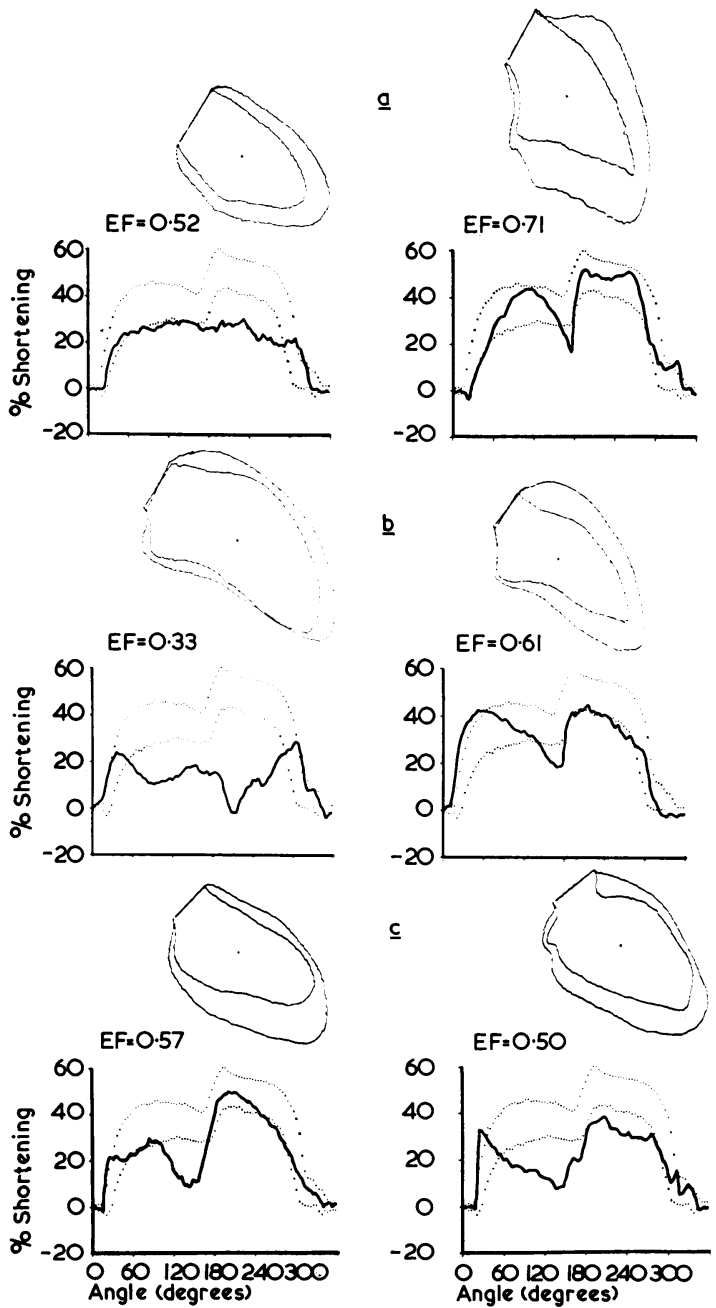

Fig. 7 a-c Computerised radial analysis of segmental wall motion before (left hand panel) and after (right hand panel) operation in three patients. Percentage shortening of radials (vertical axis) is plotted against angle in degrees around the ventricular perimeter (horizontal axis). The dotted lines indicate the normal values \pm 2 standard deviations in a group of 30 normal patients. EF, ejection fraction. (See text for details.) of the apical vent after valve replacement and a graft to the right coronary artery. Ejection fraction increased from 0.52 to 0.71 . Fig. $7 \mathrm{~b}$ illustrates a patient with generalised hypokinesia affecting most of the anterior and the inferior surface. After operation the contraction pattern returned to within normal limits and the ejection fraction increased from 0.33 to 0.61 . This patient had a graft to the anterior descending artery. The right coronary artery was also severely diseased but was a non-dominant vessel and was, therefore, not grafted. Fig. 7c illustrates a patient with anterior hypokinesia before operation who sustained anterior and inferior perioperative infarction with subsequent extension of anterior hypokinesia and the appearance of slight inferior hypokinesia. Ejection fraction decreased from 0.57 to 0.50 . A single graft was inserted into the anterior descending artery and this was found to be patent, with good distal run-off. The right coronary artery and circumflex artery showed only minor irregularities.

\section{Discussion}

Most patients in this series derived considerable benefit from combined homograft replacement of the aortic valve and coronary artery bypass grafting, both in terms of relief of symptoms and in improvement in the quality of life. Actuarial analysis of survival has shown that the early and late mortality of the combined procedure is not significantly different from that we have reported for patients undergoing isolated, elective homograft replacement of the aortic valve (Thompson et al., 1977). However, the number of patients in the combined series is small and the duration of follow-up is shorter in this group and further evaluation is required. Though many studies (Loop et al., 1972; Oury et al., 1972; Anderson et al., 1973; Cooley et al., 1973; Berndt et al., 1974; Berger et al., 1975; Callard et al., 1976) have shown that aortic valve replacement can be safely combined with coronary artery bypass grafting, other authors have reported an increased operative and late mortality with a high incidence of postoperative myocardial infarction (Loop et al., 1977).

Although perioperative myocardial damage in the present series was assessed using electrocardiographic criteria alone, the incidence of infarction was similar to that we have reported for coronary artery bypass grafting alone (Yacoub et al., 1976). No late infarctions have occurred to the present time. Unfortunately there is no comparable prospective series in which the results of isolated aortic valve replacement can be evaluated, in terms of mortality and incidence of myocardial infarction, in patients 
known to have coronary artery disease. Our experience with such patients is limited to seven patients who, though known to have coronary artery disease, underwent isolated aortic valve replacement before we started to perform the combined procedure. Two of these patients had a perioperative infarction and five of the seven patients have since died, the cause of death being left ventricular failure consequent on myocardial infarction in each case (Thompson et al., 1979b).

Although adequate myocardial protection is of great importance, there have been no significant differences in the extent of myocardial injury in reported series using a variety of current techniques (Sapsford et al., 1974; Karp and Lell, 1976). Similarly the sequence of valve replacement and bypass grafting does not appear significantly to influence the extent of myocardial damage. Rossiter et al. (1974) reported a higher incidence of myocardial damage after coronary perfusion, which may have been the result of injury to the coronary ostia during cannulation (Heilbrunn and Zimmerman, 1965; Ramsey et al., 1967) or inadequate subendocardial perfusion in the fibrillating, hypertrophied ventricle (Hottenrott et al., 1973). However, the incidence of perioperative infarction in their series was not significantly different from that in a group of patients using hypothermia alone. It has been our practice to combine continuous coronary perfusion of a beating heart with moderate degrees of hypothermia.

The cause of poor left ventricular function in patients with aortic stenosis remains uncertain. In these patients, in addition to the increased myocardial oxygen demand, myocardial perfusion may be greatly reduced even in the absence of coronary artery disease (Fallen et al., 1967). A prolonged systolic ejection time and tachycardia reduce the time available for diastolic coronary filling, particularly in the subendocardial regions (Vincent et al., 1974). Other factors limiting myocardial blood flow include increased systolic left ventricular wall tension (Rodbard et al., 1964), low mean aortic pressure, and abnormal flow patterns in the aortic root (Bellhouse and Bellhouse, 1969). Long-standing relative coronary insufficiency may lead to progressive changes in myocardial architecture and in the myocardial ultrastructure (Maron et al., 1975; Naeye and Liedtke, 1976; Schwarz et al., 1978). Additional coronary artery disease may increase the severity of these changes and lead to further deterioration in left ventricular function and myocardial infarction. Recent work has suggested that though increased afterload contributes to the development of impaired left ventricular function it is not a major determinant of myocardial per- formance (Liedtke et al., 1976). Similarly, we found no correlation between severity of aortic stenosis and extent of depression of left ventricular function (Thompson et al., 1979b). Changes in left ventricular function after valve replacement are therefore unlikely to be related simply to changes in left ventricular afterload.

Improvement in left ventricular function, as judged by changes in segmental wall motion and ejection fraction, occurred in the majority of patients reinvestigated in this series, and appeared to be closely related to graft patency and the presence or absence of previous infarction. It is not possible, however, to determine the extent to which improvement in left ventricular function could be expected with valve replacement alone, as opposed to the combined procedure. Limited data (Thompson et al., 1979b) suggest that short-term improvement in left ventricular function may occur after valve replacement in patients with coronary artery disease in the absence of additional coronary bypass grafting. However, subsequent follow-up of such patients indicates that progressive coronary artery disease results in further deterioration in left ventricular function usually consequent on myocardial infarction.

The good clinical results, with low early and late mortality of combined valve replacement and coronary artery bypass grafting, have encouraged us to believe that this is a valuable procedure which in the longer term may favourably influence the prognosis and reduce late myocardial infarction in patients with aortic stenosis and coronary heart disease.

We wish to thank Ms Margaret Rehahn and Dr S. C. Rogers for performing the statistical analysis of our data and for their advice on statistical methods.

\section{References}

Anderson, R. P., Bonchek, L. I., Wood, J. A., Chapman, R. P., and Starr, A. (1973). The safety of combined aortic valve replacement and coronary bypass grafting. Annals of Thoracic Surgery, 15, 249-255.

Basta, L. L., Raines, D., Najjar, S., and Kioschos, J. M. (1975). Clinical haemodynamic and angiographic correlates of angina pectoris in patients with severe aortic valve disease. British Heart fournal, 37, 150-157.

Bellhouse, B., and Bellhouse, F. (1969). Fluid mechanics of model normal and stenosed aortic valves. Circulation Research, 25, 693-704.

Berger, T. J., Karp, R. B., and Kouchoukos, N. T. (1975). Valve replacement and myocardial revascularisation. Circulation, 51 and 52, Suppl. I, 126-132.

Berndt, T. B., Hancock, E. W., Shumway, N. E., and Harrison, D. C. (1974). Aortic valve replacement with and without coronary artery bypass surgery. Circulation, 50, 967-971. 
Callard, G. M., Flege, J. B., jun, and Todd, J. C. (1976). Combined valvular and coronary artery surgery. Annals of Thoracic Surgery, 22, 338-342.

Cooley, D. A., Dawson, J. T., Hallman, G. L., Sandiford, F. M., Wukasch, D. C., Garcia, E., and Hall, R. J. (1973). Aorto-coronary saphenous vein bypass. Annals of Thoracic Surgery, 16, 380-390.

Fallen, E. L., Elliott, W. C., and Gorlin, R. (1967). Mechanisms of angina in aortic stenosis. Circulation, 36, 480-488.

Gula, G., Ahmed, M., Thompson, R., Radley-Smith, R., and Yacoub, $M$. (1976). Combined homograft replacement of the aortic valve and aortic root with reimplantation of the coronary arteries (abstract). Circulation, 53 and 54, Suppl. II, 150.

Hancock, E. W. (1977). Aortic stenosis, angina pectoris and coronary artery disease. American Heart fournal, 93, 382-393.

Harris, C. N., Kaplan, M. A., Parker, D. P., Dunne, E. F., Cowell, H. S., and Ellestad, M. H. (1975). Aortic stenosis, angina and coronary artery disease. Inter-relations. British Heart fournal, 37, 656-661.

Heilbrunn, A., and Zimmerman, J. M. (1965). Coronary dissection: a complication of cannulation. Fournal of Thoracic and Cardiovascular Surgery, 49, 767-771.

Hottenrott, C. E., Towers, B., Kurkji, H. J., Maloney, J. V., and Buckberg, G. D. (1973). The hazard of ventricular fibrillation in hypertrophied ventricles during cardio-pulmonary bypass. Fournal of Thoracic and Cardiovascular Surgery, 66, 742-753.

Karp, R. B., and Lell, W. (1976). Evaluating techniques of myocardial preservation for aortic valve replacement: operative risk. Fournal of Thoracic and Cardiovascular Surgery, 72, 206-208.

Liedtke, A. J., Gentzler, R. D., II, Babb, J. D., Hunter, A. S., and Gault, J. H. (1976). Determinants of cardiac performance in severe aortic stenosis. Chest, 69, 192-200.

Linhart, J. W., de la Torre, A., Ramsey, H. W., and Wheat, M. W., jun (1968). The significance of coronary artery disease in aortic valve replacement. Fournal of Thoracic and Cardiovascular Surgery, 55, 811-819.

Linhart, J. W., and Wheat, M. W., jun (1967). Myocardial dysfunction following aortic valve replacement. Fournal of Thoracic and Cardiovascular Surgery, 54, 259-269.

Loop, F. D., Favaloro, B. G., Shirley, E. K., Groves, L. K., and Effler, D. B. (1972). Surgery for combined valvular and coronary heart disease. Fournal of the American Medical Association, 220, 372-376.

Loop, F. D., Phillips, D. F., Roy, M., Taylor, P. C., Groves, L. K., and Effler, D. B. (1977). Aortic valve replacement combined with myocardial revascularization. Circulation, 55, 169-173.

Mandal, A. B., and Gray, I. R. (1976). Significance of angina pectoris in aortic valve stenosis. British Heart fournal, 38, 811-815.

Maron, B. J., Ferrans, V. J., and Roberts, W. C. (1975). Myocardial ultrastructure in patients with chronic aortic valve disease. American fournal of Cardiology, 35, 725-739.

Moraski, B. E., Russel, R. O., Mantle, J. A., and Rackley, C. E. (1976). Aortic stenosis, angina pectoris, coronary artery disease. Catheterization and Cardiovascular Diagnosis, 2, 157-164.

Naeye, R. I., and Liedtke, A. J. (1976). Consequences of intramyocardial arterial lesions in aortic valvular stenosis. American fournal of Pathology, 85, 569-578.
Oury, J. H., Quint, R. A., Angell, W. W., and Wuerflein, R. D. (1972). Coronary artery vein bypass grafts in patients requiring valve replacement. Surgery, 72, 1037-1047.

Paquay, P. A., Anderson, G., Diefenthal, H., Nordstrong, L., Richman, H., and Gobel, F. L. (1976). Chest pain as a predictor of coronary artery disease in patients with obstructive aortic valve disease. American fournal of Cardiology, 38, 863-869.

Ramsey, H. W., de la Torre, A., Linhart, J., and Wheat, M. W., jun (1967). Complications of coronary artery perfusion. Fournal of Thoracic and Cardiovascular Surgery, 54, 714-718.

Rickards, A., Seabra-Gomes, R., and Thurston, P. (1977). The assessment of regional abnormalities of the left ventricle by angiography. European fournal of Cardiology, 5, 167-182.

Rodbard, S., William, C. B., Rodbard, D., and Berglund, E. (1964). Myocardial tension and oxygen uptake. Circulation Research, 14, 139-149.

Rossiter, S. J., Hultgren, H. N., Kosek, J. C., Wuerflein, R. D., and Angell, W. W. (1974). Ischemic myocardial injury with aortic valve replacement and coronary bypass. Archives of Surgery, 109, 652-658.

Sandler, M., and Dodge, H. T. (1968). The use of single plane angiocardiograms for the calculation of left ventricular volume in man. American Heart fournal, 75, 325-334.

Sapsford, R. N., Blackstone, E. H., Kirklin, J. W., Karp, R. B., Kouchoukos, N. T., Pacifico, A. D., Roe, C. R., and Bradley, E. (1974). Coronary perfusion versus cold ischaemic arrest during aortic valve surgery: a randomised study. Circulation, 49, 1190-1199.

Schwarz, F., Flameng, W., Schaper, J., Langebartels, F., Sesto, M., Hehrlein, F., and Schlepper, M. (1978). Myocardial structure and function in patients with aortic valve disease and their relation to post-operative results. American fournal of Cardiology, 41, 661-669.

Thompson, R., Ahmed, M., Mitchell, A. G., Towers, M. K., and Yacoub, M. H. (1979a). Angina, aortic stenosis and coronary heart disease. Clinical Cardiology 2, 26-32.

Thompson, R., Knight, E., Ahmed, M., Somerville, W., Towers, M. K., and Yacoub, M. H. (1977). The use of fresh unstented homograft valves for replacement of the aortic valve. Circulation, 56, 837-841.

Thompson, R., Yacoub, M. H., Ahmed, M., Seabra-Gomes, R., Rickards, A., and Towers, M. K. (1979b). The influence of pre-operative left ventricular function on the results of homograft replacement of the aortic valve for aortic stenosis. American fournal of Cardiology, 43, 929-938.

Vincent, W. R., Buckberg, G. D., and Hoffman, J. I. E. (1974). Left ventricular subendocardial ischaemia in severe valvar and supravalvar aortic stenosis. Circulation, 49, 326-333.

Yacoub, M., Ahmed, M., Fawzy, E., and Gula, G. (1976). Myocardial infarction in patients undergoing coronary artery bypass grafting (abstract). British Heart fournal, 38, 315.

Yacoub, M., Knight, E., and Towers, M. K. (1973). Aortic valve replacement using fresh unstented homografts. Thoraxchirurgie, 21, 451-457.

Requests for reprints to M. Yacoub, Esq., F.R.C.S., Harefield Hospital, Harefield, Middlesex UB9 6JH. 